\title{
Prácticas cinéfilas en la escuela media argentina: mirar, hablar y transmitir el discurso del cine
}

\author{
Ariel Benasayag ${ }^{1}$ (1) \\ Universidad Nacional de Cuyo, Argentina
}

Autor de correspondencia: 1abenasayag@gmail.com Recibido: 4 de noviembre de 2020 Revisado: 7 de noviembre de 2020 Aprobado: 2 de marzo de 2021 Publicado: 8 de abril de 2021

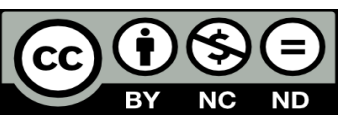

\section{Resumen}

En el artículo se pretende contribuir a la reflexión sobre los vínculos entre escuela y cine. Se parte de la hipótesis de que los modos de incorporación pedagógica del cine de ficción en la escuela media argentina contemporánea están relacionados con las prácticas de los docentes como espectadores. Con este horizonte interpretativo, se revisan definiciones y caracterizaciones sobre los cinéfilos y se introduce el concepto de cinefilia, entendida como un modo de mirar y mostrar películas, de reflexionar y hablar sobre ellas y de transmitir el discurso del cine. El estudio de casos es la estrategia metodológica. Los testimonios se obtuvieron en entrevistas realizadas a dos docentes cinéfilos. En el trabajo se describen saberes y se analizan prácticas pedagógicas en las que parecen desplegarse las relaciones entre cultura cinematográfica y cultura escolar. Finalmente, teniendo en cuenta la discusión sobre el potencial de la experiencia artística en tanto alteridad de la forma escolar, se piensan los casos estudiados como posibles, aunque inciertos, encuentros con el cine $-\mathrm{y}$ con la cinefilia-.

Palabras clave: escuela, docente, cine, espectador, cinefilia, práctica pedagógica 


\title{
Cinephile practices in Argentinean middle school: watching, talking, and teaching the discourse of cinema
}

\begin{abstract}
The article aims to contribute to the reflection on the links between school and cinema. The hypothesis is that the pedagogical incorporation of fiction cinema in contemporary Argentinean middle schools is related to teachers' practices as spectators. From this perspective, definitions and characterizations on cinephiles are reviewed and the concept of cinephilia is introduced, understood as a way of watching and presenting films, of reflecting and talking about them, and of transmitting the discourse of cinema. The case study is the methodological strategy. The testimonies were obtained from interviews with two teachers who are cinephiles. In this article, knowledge and pedagogical practices are described and analyzed, in which the relations between film culture and school culture seem to be displayed. Finally, taking into account the discussion on the potential of the artistic experience as an alterity of the school experience, the cases studied are considered as possible, albeit uncertain, encounters with cinema-and with cinephilia.
\end{abstract}

Keywords: school, teacher, cinema, spectator, cinephilia, pedagogical practice

\section{Práticas cinéfilas na escola média argentina: assistir, falar e ensinar o discurso do cinema}

\section{Resumo}

O artigo visa contribuir para a reflexão sobre os vínculos entre a escola e o cinema. A hipótese é que a incorporação pedagógica do cinema de ficção nas escolas secundárias argentinas contemporâneas está relacionada com as práticas dos professores como espectadores. Nesta perspectiva, são revisadas definições e caracterizações sobre os cinéfilos e o conceito de cinefilia é introduzido, entendida como uma forma de assistir e apresentar filmes, de refletir e falar sobre eles, e de transmitir o discurso do cinema. O estudo de casos é a estratégia metodológica. Os testemunhos foram obtidos de entrevistas com dois professores que são cinéfilos. Neste artigo, são descritos e analisados conhecimentos e práticas pedagógicas, nos quais as relações entre a cultura cinematográfica e a cultura escolar parecem ser expostas. Finalmente, levando em conta a discussão sobre o potencial da experiência artística como alteridade da experiência escolar, os casos estudados são considerados como possíveis, ainda que incertos, encontros com o cinema - e com a cinefilia.

Palavras-chave: escola, docente, cinema, espectador, cinefilia, prática pedagógica 
Es como dice Robin Williams en Retratos de una obsesión (2002): "Es detener el tiempo en algo que vale la pena”; detener el tiempo en una foto. Yo coincido muchísimo con eso.

-Leandro

El testimonio de Leandro, docente de psicología en una escuela pública argentina de nivel medio, fue obtenido en el marco de la investigación Escuela, jóvenes y saberes ${ }^{1}$. Llama la atención que, para definir su relación con la fotografía, evoque espontáneamente la frase de una película, que la haya memorizado y la utilice con naturalidad para explicar(se) en una conversación. Cuando cuenta que incorpora frecuentemente cine de ficción en sus prácticas pedagógicas, respecto de lo que sucede en el aula cuando pasa una película, describe:

- Traigo una secuencia armada para analizar la película. Primero la presento: "el director es este, el productor es este, estos son los actores". El otro día trabajamos con una de Robin Williams. Yo les digo: "Díganme películas con Robin Williams". "Una noche en el museo (2006)", dicen. "Hay dos películas en las que el tipo trabaja de loco: Retratos de una obsesión (2002) y Noches blancas (2002); Noches blancas van a ver ustedes", y justo la estaban dando por el cable, me dijeron. Entonces les marco lo enorme que es este actor. Les cuento cosas de atrás de la película que me he enterado [...] Esas cosas yo las marco, primero, porque le da pasión al contenido, y entonces ya no estamos viendo una película, estamos compartiendo un hecho cultural. Yo necesito meterle pasión a mis clases [...] Les fascinaba. No sabés al nivel de análisis que llegaron, porque encontraron en mi materia un elemento humano [...] La imagen termina siendo un elemento integrador.

Aquella investigación mostró dos cosas respecto de la incorporación del cine en la escuela argentina contemporánea: en primer lugar, que el uso escolar de películas de ficción es una práctica frecuente y extendida entre los docentes de nivel medio de materias curriculares de las áreas sociales y humanísticas, tecnológicas y estéticas (Benasayag, 2012). Aun cuando esto no implica necesariamente la existencia de nuevas o diferentes concepciones acerca del cine en el discurso pedagógico (Serra, 2011) y, por lo tanto, tampoco transformaciones en los motivos, objetivos o modos de incorporación escolar, destaca la aceptación generalizada y el entusiasmo con el que numerosos docentes se refieren al uso de películas en el aula. Es posible hipotetizar que este prestigio del que gozan las ficciones cinematográficas evidencia un desplazamiento en los saberes tradicionalmente legitimados por el discurso pedagógico: de alguna manera, el cine ha comenzado a formar parte del canon cultural que merece ingresar y ser transmitido en la escuela.

Esta observación resulta significativa en relación con la valoración que el cine ha adquirido en sus más de ciento veinte años frente a otros productos de la cultura de masas. Además, es pertinente respecto de los modos como históricamente ingresó en las escuelas argentinas (Abramowski, 2015; Dussel, 2014; Paladino, 2006; Serra, 2011). En este sentido, más allá de los debates sobre su cualidad artística o su utilización pedagógica, no ha sido tradicionalmente el gobierno educativo nacional el promotor dela incorporación escolar de la ficción cinematográfica (Benasayag, 2020). En lo referente a las últimas dos décadas, si bien han aparecido valiosos programas ministeriales - pertinentes e interesantes en sus concepciones-, por diversas razones, su alcance temporal o territorial resultó limitado y quedó trunco.

1 Realizada en 2011, fue dirigida por I. Dussel. Con una finalidad exploratoria y descriptiva, la pesquisa contó con un diseño metodológico mixto cuyos instrumentos fueron aplicados a una muestra teórica constituida por docentes y estudiantes de escuelas de nivel medio del sistema educativo argentino (Dussel et al., 2011). 
Asimismo, aunque algunas jurisdicciones disponen de orientaciones curriculares vinculadas con la comunicación, las artes o las ciencias sociales en el nivel medio, el cine no es actualmente una asignatura independiente ni, salvo algunas excepciones, un contenido específico. No abundan en las escuelas públicas ni en las de gestión privada propuestas institucionales estructuradas que tengan como fin la enseñanza sobre o con ficciones cinematográficas, como tampoco sobre medios ni con imágenes en general. Sí hay cada vez más publicaciones de enfoque didáctico sobre estos temas. Por lo tanto, es posible concluir que ese uso frecuente y extendido de películas que manifiestan los docentes es impulsado menos desde arriba - el gobierno educativo nacional, la administración escolar provincial, la gestión institucional- que desde abajo. Aparentemente, el cine ingresa al aula a partir de las iniciativas de los propios docentes.

Adquiere así relevancia el segundo hallazgo: aquella pesquisa mostró también que gran parte de los docentes que afirman utilizar frecuentemente películas en sus clases, en tanto espectadores mediáticos, legitiman con igual fervor su consumo privado de cine. Un tercio de los entrevistados expresó ser consumidor asiduo de ficciones cinematográficas, quizá debido a ese prestigio que reviste el cine ante otros productos culturales de aparición más reciente, como los videojuegos. De este modo, si de describir e interpretar los modos de incorporación pedagógica del cine de ficción en la escuela media argentina contemporánea se trata, cabe detenerse en el potencial explicativo de la relación entre las formas de consumo mediático y los usos escolares (Benasayag, 2017)2.

El testimonio evocado inicialmente permite pensar el vínculo entre consumo mediático y usos escolares como una cierta forma de cinefilia. En este sentido, resulta apropiado partir de una definición ampliamente aceptada en los estudios sobre esta práctica, aquella que Baecque y Frémaux (1995) formularon con una sencillez tal que permite identificar tanto las particularidades de la práctica como las de los sujetos que la realizan: los cinéfilos no son simples espectadores, ni siquiera consumidores habituales de cine; la cinefilia es un modo peculiar de mirar películas y de apropiárselas, una determinada manera de reflexionar y hablar sobre ellas con otros, un compromiso público de transmitir el discurso del cine y, entonces, también, el de la cinefilia.

Esta lectura de la propuesta conceptual que de Baecque y Frémaux (1995) hacen para estudiar la cinefilia clásica francesa entre 1944 y 1968 resulta apropiada para interpretar la relación tanto de aquel docente como de otros profesores con las películas, para analizar sus prácticas con el cine como espectadores y profesores, fuera y dentro del aula ${ }^{3}$. En el testimonio de Leandro aparece una forma de mirar películas en el cual la admiración y la identificación con las estrellas y los personajes que encarnan son dimensiones significativas, tanto como ciertos datos o anécdotas de la producción. Es posible advertir también un modo de apropiación de las ficciones cinematográficas para la propia vida, cuando la película funciona a la vez como dispositivo de pensamiento y de expresión de sus ideas.

2 No adoptamos aquí una posición determinista que atribuya una razón única a las prácticas sociales, sino la consideración de que estas responden a una pluralidad de disposiciones internas y externas. Así, la condición de espectador esporádico o cinéfilo de un docente no se traduce necesaria ni directamente en la incorporación o en determinados usos del cine en el contexto del aula.

3 La definición fue elaborada con el fin de explicar las prácticas de críticos y cineastas parisinos agrupados en torno a la revista Cahiers du Cinéma. Dicha cinefilia promovió un modo de legitimación de obras y autores, a partir de la defensa del cine como arte realista y la política de los autores. Salvando las distancias, trataremos de mostrar que es posible identificar un horizonte común entre aquellos cinéfilos y las prácticas cinéfilas de estos docentes. 
Asimismo, hay situaciones de intercambio con los estudiantes, organizadas en torno al cine y al conjunto de saberes sobre las películas: filmografías, formas de circulación. Y aparece, finalmente, más allá del motivo que convoca a los participantes — la enseñanza escolar de una disciplina curricular-, el compromiso personal, afectivo, con el propio gusto y con el objeto de placer: la difusión del cine en el marco del aula, el momento en que tanto docente como estudiantes son más espectadores que sujetos escolares; cuando las películas, más allá de su dimensión educativa o del objetivo didáctico que justifica su presencia, son compartidas como obras de arte, productos de culto, fuentes de entretenimiento. Intuimos allí la transmisión de una cinefilia, entendida como un modo de mirar y reflexionar sobre las películas, pero, ante todo, como una pasión por el cine, una experiencia con el cine que merece ser compartida con otros.

\section{Metodología}

Formulamos entonces la hipótesis de este trabajo: cuando el cine no ingresa de manera curricular en las aulas — aunque, quizá, incluso cuando sí lo hace-, en esas prácticas cinéfilas desplegadas en medio de cualquier clase se juega la relación entre cultura escolar y cultura cinematográfica. En los próximos apartados proponemos describir y reflexionar sobre las cualidades de estas prácticas cinéfilas que tienen lugar en el aula a partir del análisis de los testimonios de dos profesores: Ignacio ${ }^{4}$ y Ramiro ${ }^{5}$, a quienes, luego de considerar tanto sus prácticas de consumo cinematográfico como de incorporación escolar de películas, identificamos como docentes cinéfilos. Dichos testimonios fueron obtenidos en el marco de la investigación El cine de ficción en la escuela argentina: un estudio de casos sobre las prácticas cinéfilas de docentes de nivel medio dentro y fuera del aula, presentada como tesis en el marco de la Maestría en Ciencias Sociales con orientación en Educación de Flacso Argentina en 2020. Se trató de una investigación cualitativa con sensibilidad etnográfica, en la que definimos al estudio de casos como metodología y a la entrevista en profundidad como técnica (Arfuch, 1995).

\section{Definiciones y caracterizaciones sobre las prácticas cinéfilas}

Baecque y Frémaux (1995) definen la cinefilia a través de un breve enunciado, recuperado en numerosas ocasiones como primer e ineludible modo de delimitar la práctica. Para ellos, la cinefilia es "una forma de ver películas, hablar sobre ellas y difundir luego ese discurso" (p. 133). Su acierto quizá radique en haber podido condensar con notable claridad tres acciones que constituyen las prácticas cinéfilas y que, dispuestas de manera secuencial, establecen como premisa que se trata de una práctica individual siempre realizada con y hacia otros: lejos de encontrar su punto de culminación en el desarrollo de un modo particular y propio de mirar -o amar- películas, la cinefilia implica una relación afectiva con el cine que se despliega comunitariamente en los intercambios con otros cinéfilos y en la transmisión de ese discurso que es el del cine pero, también y sobre todo, el de la cinefilia.

4 Ignacio es licenciado en comunicación social. Al momento de la entrevista —2012 —, tiene 37 años y suma 11 de antigüedad docente en la misma escuela de nivel medio de gestión privada en la que trabaja 12 horas-cátedra semanales como docente del área de comunicación.

5 Ramiro es profesor y licenciado en filosofía. Al momento de la entrevista - 2012 —, tiene 44 años y suma 9 de antigüedad docente. Trabaja un total de 29 horas-cátedra semanales distribuidas entre dos escuelas privadas en las que enseña antropología y filosofía. 
Sin embargo, para los cinéfilos parisinos que describen, la relación con las películas llegaba aún más lejos. Su texto deja ver cómo el cine se imbricaba, se confundía con la vida misma: la cinefilia era una forma de "vida organizada en torno del cine", una "necesidad vital". En este sentido, la cinefilia aparece como "algo misterioso, ritual, enigmático, secreto", en tanto es experimentada como una "pasión", casi religiosa, compartida con "el clan", los colegas de la revista o los miembros del cineclub en tanto "comunidad de interpretación" (Baecque \& Frémaux, 1995, p. 134).

Del otro lado del océano, los estudios de Jenkins (2009) sobre la cultura fan también contribuyen en la caracterización de las prácticas cinéfilas, aun cuando no trabajó específicamente el tema. Él se esforzó en construir una imagen alternativa de los aficionados, al mostrar a los consumidores de la cultura de masas como "sujetos activos, críticamente comprometidos y creativos" que poseen saberes y habilidades necesarias para "archivar, comentar, apropiarse de los contenidos mediáticos y volver a ponerlos en circulación" (p. 10). No alcanza con ser espectador habitual de un producto audiovisual para convertirse en fan, sino que es necesario además "traducir ese visionado en algún tipo de actividad cultural, compartiendo con amigos sentimientos y pensamientos sobre el contenido del programa, uniéndose a una comunidad de otros fans que comparten intereses comunes" (p. 12). En efecto, lo que define la cultura de los fans es la "habilidad de transformar la reacción personal en interacción social, la cultura del espectáculo en cultura de la participación" (p. 12).

Staiger (2005) recuperó los desarrollos de Jenkins para pensar las prácticas de los movie fans. La autora sintetiza seis categorías que describen las prácticas de afición, que pueden ser entendidas como una forma particular de cinefilia:

1. La adopción de "un modo distintivo de recepción" caracterizado por la anticipación, la repetición y la ritualización.

2. La conformación o adhesión a "una comunidad de interpretación", como una "red de colegas" que debaten grupalmente y transmiten a los nuevos miembros estrategias de lectura a partir de la explicación de distintos aspectos del cine.

3. El establecimiento de "una base para el activismo de consumidor".

4. La construcción de "un particular mundo artístico", la creación en torno a los productos de afición, las prácticas de producción cultural propias del fandom.

5. La integración de "productos de afición en la vida cotidiana" — colección-.

6. La constitución de "una comunidad alternativa" que, a modo de "subcultura" o "contracultura", promueve la realización de interacciones grupales y actividades compartidas (Staiger, 2005).

A pesar de las evidentes diferencias en los repertorios legitimados por unos y otros, no resulta difícil encontrar los puntos de contacto entre las prácticas de los cinéfilos parisinos de los Cahiers y las prácticas de afición de los movie fans.

Por su parte, para Jullier y Leveratto (2012) la cinefilia "designa inseparablemente el hecho de que el espectador hace hablar a las películas de su calidad" y que "las películas llevan a los espectadores a hablar de su placer" (p. 31). Concluyen así que solo es posible 
analizar las prácticas cinéfilas al observar los intercambios entre "cinéfilos anónimos" que promueven las películas y, a su vez, se ven reforzados por las discusiones que provocan entre ellos. Tal como lo entienden, lo significativo en estas conversaciones es el placer que produce hablar de una cierta película específica y no de otra. A la vez, el juicio se apoya en una memoria personal cinematográfica, en las películas antes vistas y, sobre todo, en aquellas que dejaron una marca. En este sentido, los autores destacan que "lo importante es el hecho de que yo cultivo el placer que me proporcionan las películas y que, al hacerlo, las películas me cultivan" (p. 32). Finalmente, comprenden la incorporación de la cultura cinematográfica como "un aprendizaje intuitivo, que confiere la competencia para actuar [...], un saber de la situación" que, de ese modo, posibilita la doble "interiorización afectiva y absorción cognitiva que caracteriza la participación en el espectáculo cinematográfico y que permite que se extraiga placer de él" (p. 35).

Por último, desde la perspectiva de la postcinematografía, Valck y Hagener (2005) complementan la concepción de cinefilia con la noción de videosincracia, al intentar dar cuenta del "movimiento fluido [de los actuales cinéfilos] entre diferentes tecnologías, plataformas y posiciones subjetivas de una forma marcadamente idiosincrática que, sin embargo, permanece lo suficientemente conectiva y flexible como para posibilitar el intercambio subjetivo de afectos, objetos y memorias" (p. 14). Esta perspectiva habilita la consideración de la práctica cinéfila entendida como un "acto de memoria" en el marco de un "imaginario fílmico-histórico" (Robnik, 2005). De este modo, en su relación con la historia y la memoria del cine, las prácticas cinéfilas se abren actualmente a un juego de reelaboración del imaginario histórico-fílmico, que constituye un "almacén sin límites que puede ser saqueado para obtener tropos, objetos, expresiones, estilos e imágenes de obras anteriores" (Valck \& Hagener, 2005, p. 15).

\section{Docentes cinéfilos y prácticas cinéfilas en la escuela}

Las diversas teorizaciones propias del campo de estudio sobre cinefilia exhiben diferencias respecto de a quiénes considerar legítimos cinéfilos: si solo a ciertos eruditos, si también a cada aficionado, si a los incontables anónimos que comparten los placeres que experimentan al participar de la cultura cinematográfica. Al mismo tiempo, cada perspectiva discute el potencial explicativo y la centralidad relativa de las múltiples dimensiones identificadas en las formas que, desde mediados del siglo XX, fueron adoptando las distintas cinefilias: ciertos rituales, algún modo de registro, aquella colección, el clan, los intercambios, determinadas formas del afecto, un imaginario histórico-fílmico.

Sin embargo, todas parecen coincidir en que las prácticas cinéfilas, de un modo u otro, implican una forma de ver películas, hablar sobre ellas y difundir luego ese discurso. No es otra cosa lo que dice Jenkins (citado por en Staiger, 2005) cuando describe la cultura fan como la adopción de un modo de recepción y la conformación de una comunidad de interpretación con el fin de debatir y transmitir el cine, lo cual establece así un tipo de activismo; o lo que sostienen Jullier y Leveratto (2012) cuando atribuyen a los sujetos la libertad de desarrollar cierta sensibilidad artística frente a la técnica del arte cinematográfico, que los habilita a experimentar las emociones que produce, compartirlas con otros y transmitir ese placer.

Comprendidas en este sentido, las prácticas con el cine que Ignacio y Ramiro llevan a cabo como docentes permiten identificar el despliegue de sus particulares formas de 
cinefilia en el contexto del aula. Estos casos confirman la hipótesis de que el vínculo que los sujetos desarrollan y experimentan con el cine en tanto espectadores luego influye de diversas maneras y en diferente grado en sus prácticas escolares. Aparentemente, esta influencia tiene lugar en relación con — pero también más allá de- sus fines pedagógicos particulares, las cualidades de sus procesos de formación y la especificidad disciplinar de las materias que enseñan.

$\mathrm{Al}$ respecto, el análisis de sus prácticas permite advertir que, aun cuando ciertos aspectos de la transmisión cinéfila no son siempre, ni de manera explícita, fines en sí mismos, en general parecen deslizarse en las actividades que proponen, o bien teñir sus objetivos pedagógicos, motivos de incorporación, criterios de selección o repertorios. En los próximos apartados avanzamos en ese sentido. Se describen prácticas de cinefilia docente que pueden calificarse como más o menos directas o indirectas, dado que las formas particulares de cada subjetividad no pueden sino amalgamar — al permear cualquier frontera imaginariasus cualidades como espectador y como docente, la cuales discriminamos en cada paso para comprenderlas.

Las experiencias de estos docentes cinéfilos son relevantes porque permiten percibir los límites y alcances de los vínculos entre prácticas culturales desarrolladas fuera y dentro de la escuela; y porque, más allá de sus puntos de convergencia, son prácticas notablemente diferentes entre sí. Basta con considerar las distancias entre los placeres cinéfilos que cada uno identifica y expresa: los rituales en el caso de Ramiro, el análisis de la narración cinematográfica para Ignacio; o los distintos saberes de los que disponen sobre el cine y los modos en que influyen en sus criterios de selección y propuestas de incorporación -la apropiación intuitiva del primero y las múltiples instancias y diversas perspectivas de formación que caracterizan la trayectoria del segundo-.

Sin embargo, a propósito de las características particulares de las prácticas cinéfilas como las hemos definido, es posible identificar correspondencias significativas entre las prácticas escolares que ambos llevan a cabo, por un lado, en sendas propuestas de dar a mirar repertorios precisos, de hablar sobre películas específicas y de transmitir ciertas concepciones sobre el cine; y por otro, en la aparente militancia a favor de la cultura cinematográfica que tiene lugar dentro del aula, evidente especialmente en el caso de Ramiro. Esta iniciativa, al promover la legitimación de "otras" cinematografías y de "otros" modos de mirar, espera producir —si no entonces, quizá después- diferentes encuentros con el cine, acaso en los términos que lo propone Bergala (2007).

\section{Una forma particular de (dar a) mirar películas}

A propósito de la utilización del cine en la escuela, Ramiro afirma:

- Yo creo que pasar cine depende mucho del profe, que le dé un significado a la película, que sea un momento pedagógico y artístico, ciertamente identificados.

No está en desacuerdo con la idea de una incorporación formal, curricular, pero le resulta indiferente, acaso porque, como en el caso de Ignacio, su testimonio da cuenta de una concepción de la inclusión escolar del cine que, ante todo, atribuye al docente el rol de "pasador" o "mediador" en el sentido que lo propone Bergala (2007). Así, antes de pensar en la posibilidad de que ingrese de otros modos, Ramiro prefiere remitirse a su propia práctica 
cinéfila: a la valoración de la ritualización de la experiencia de mirar, hablar y transmitir el discurso del cine en la escuela:

- Siempre he sostenido la necesidad de crear un espacio como de cineclub; un espacio de encuentro para los chicos a través de cine, con un pequeñísimo trabajo previo o posterior a la película.

Respecto de la práctica de mirar cine en el contexto escolar, específicamente cuando supone mostrar aquellas películas en las que cada quien encuentra algún placer, es decir, en relación con el propio gusto cinematográfico, Ramiro explica:

- Abiertamente no les digo [a los estudiantes]: "Miren esto, miren lo otro". Supongo que eso [desarrollar "otra mirada" atenta a "aspectos artísticos"] se debe producir por el solo hecho de ver cine más independiente.

La transmisión cinéfila comienza así en el acto de mostrar películas alternativas a las que supuestamente consumen y de considerar para esto la oferta más representativa del mercado mediático.

Sin embargo, mostrar este otro cine "independiente" no parece ser suficiente para Ramiro:

- Yo me burlo mucho del cine comercial. Las pelis que yo paso son del cine como arte, y no pierdo la oportunidad de reírme del cine comercial, de mofarme.

Define esta práctica como "una bomba que va tirando, que va debilitando la pared", al referirse a la programación de los canales de televisión, que "pasan porquería pura". También con el fin de polemizar con los estudiantes, los provoca:

- Eso es veneno [...] Cuantas más horas pasan de esas películas, es una neurona menos.

Sin embargo, cuenta que después explica "algunas cuestiones de la industria del cine yanqui”. Al reflexionar sobre estas prácticas, concluye:

- Hacés un trabajo de concientizar, de cómo el cine culturiza, impone un imaginario, una forma de vida.

En este sentido, también es posible percibir aquí la intención de educar una mirada crítica.

Por su parte, Ignacio sostiene que:

- [El cine] instala [temas distintos a los definidos en el currículum, aunque], obviamente, no los desarrolla, simplemente los presenta. [...] En muchos casos la escuela está separada de la vida [como] una instancia aparte, separada de lo ideológico, separada de lo político, separada de las concepciones del mundo que cada uno tiene.

De este modo, el entrevistado recurre al cine para cuestionar:

- Cierto rasgo objetivista que sigue presente en la escuela, como si todas las materias fueran matemática, como si no hubiera nada discutible. [...] Más allá de lo que veamos en un tema específico, [lo significativo finalmente es] cómo se concreta eso con la vida real.

Elabora un ejemplo a partir de un contenido específico de la disciplina que enseña, la noción de código: 
- Les podés plantear qué es un código: una serie de convenciones para establecer algo, y otro que lo lee desde otra distancia, el proceso de simetría; bárbaro [...] [En También la lluvia (2010)], la parte donde les explica a las mujeres que tienen que entrar con los chicos [al río]. Los chicos no se van a mojar, que después les van a poner unos muñecos y los van ahogar [y las mujeres nativas se rehúsan a hacerlo]. Bueno, hay dos concepciones de la vida completamente distintas, o sea, hay una diferencia de códigos ahí, que es necesario tener en cuenta para entender lo que está planteando la película. Entonces muchas veces es eso: tratar de escapar a la transmisión lisa y llana de un conocimiento, de una teoría, de una concepción, y tratar de instalar o construir el tema desde otro lugar. Me parece que [mi uso del cine] va más por ese lado.

En un sentido similar al descrito en el caso de Ramiro, para Ignacio:

- Mostrar otras formas de cine, otras formas de narración, es un objetivo transversal.

En su caso, esta finalidad también está estrechamente vinculada a sus propios gustos cinéfilos:

- A mí lo que me resulta más interesante, que los chicos por ahí no siempre llegan a concientizarlo [...], es la idea de un relato construido.

Como espectador, Ignacio experimenta placer a partir de las historias, pero, ante todo, del modo como están narradas, dimensiones que su formación ha contribuido a privilegiar. Así, sus prácticas de dar a mirar ficciones cinematográficas giran en torno a su interés por:

- La concepción de que cualquier producto audiovisual forma parte de un recorte, de un momento histórico, de una realidad, generalmente de manera consciente, [aunque] puede que de manera inconsciente. Digo, no es un producto ni objetivo ni objetivable, sino que tiene características propias de construcción humana, de proceso histórico; no es un elemento natural. Y también cómo el tiempo, los hábitos, terminan naturalizando ciertos procesos históricos, dándoles características de "Así fue siempre, así se hacen las cosas", [y] por lo tanto, "Esto es lo verdadero porque ya está establecido". Aunque no lo veamos [como un contenido de la materia], aunque no trabajemos una definición de eso propiamente.

De esta manera, el modo de mirar propuesto por Ignacio - a partir de su propia preocupación por la construcción de la representación cinematográfica- también parece suponer como finalidad la formación de los estudiantes como espectadores críticos, aunque menos en el sentido del "desenmascaramiento ideológico" que exhiben las prácticas de Ramiro, basadas en desarrollo de habilidades relacionadas con la especificidad del cine como lenguaje y con una concepción de las imágenes entendidas como prácticas sociales que tienen lugar en el marco de un determinado régimen visual (Dussel, 2014).

Asimismo, aproximándose a los horizontes pedagógicos, filosóficos y antropológicos que persigue Ramiro en su utilización escolar de películas, Ignacio considera que, además de los contenidos definidos curricularmente, en estas actividades:

- [Los estudiantes] aprenden que hay, que puede haber visiones muy distintas sobre las cosas, que en sí mismas no son ni correctas ni incorrectas, sino que dependerán de ciertas condiciones [y saberes que] hacen a la cultura general, al apreciar cómo pueden ser otras sociedades, otras personas. 
Fundamenta la amplitud y la diversidad de la curaduría cinematográfica que realiza al argumentar que:

- Mientras más grande sea nuestro conocimiento del mundo, más herramientas tenemos para discernir.

Cierra ilustrando el riesgo de pensar lo contrario:

- Si hay alguien más peligroso que aquel que no leyó nunca un libro, es el que leyó uno solo [...] Me parece que en eso sí enriquece [el cine], más allá de lo instructivo curricular y todo lo demás.

Finalmente, en el caso de Ignacio, las prácticas de mostrar cine exceden los límites del aula, en particular porque es reconocido como un referente en estos temas por sus pares docentes:

- A los más conocidos les recomiendo películas. [Aún sin que ellos se lo pidan], se las grabo en DVD, a veces lo pago yo nomás.

Ignacio desconoce si luego toman su sugerencia. Evidentemente no es algo que parezca importarle. En este sentido, aunque su finalidad es ampliar el repertorio cinematográfico de sus colegas, para que luego puedan incorporar también contenidos audiovisuales como recursos pedagógicos, el valor de la práctica parece estar puesto en el propio acto de brindar cine, en la práctica de hablar sobre y compartir el placer que le producen ciertas películas.

\section{Hablar sobre cine en la escuela}

En su propuesta de investigación sobre las distintas formas de cinefilia, Jullier y Leveratto (2012) identifican los intercambios entre cinéfilos como la circunstancia ideal para analizar sus prácticas, puesto que destacan que "el espectador hace hablar a las películas de su calidad" y, en el mismo movimiento, "las películas llevan a los espectadores a hablar de su placer" (p. 31). En este sentido, el acto de hablar sobre cine, en particular acerca de una película perteneciente al propio repertorio cinematográfico, es una recurrencia entre las prácticas de estos docentes cinéfilos.

Al considerar sus prácticas como espectador, y en particular los modos como Ramiro suele experimentar placer a partir del cine, no resulta extraño observar que las conversaciones que propone a los estudiantes estén relacionadas con la dimensión ritual y cultural de su propia experiencia cinematográfica:

- En mi clase se ve cine, [y] se comenta [...] Yo todos los miércoles voy al cine, entonces los jueves por lo general los chicos me preguntan: “¿Qué fuiste a ver? ¿Estuvo aburrida? ¿Estuvo buena? ¿Estuvo mala?”.

Se destaca aquí que la práctica de hablar sobre cine aparezca como una actividad rutinaria del aula, jerarquizada de manera equivalente al acto de mirar una película, pero, además, tal como relata, que sean los estudiantes quienes, al reconocer en Ramiro cierta envestidura cinéfila, habiliten los intercambios a propósito de las películas.

Por su parte, el testimonio de Ignacio aporta numerosos ejemplos respecto de las prácticas de hablar sobre la calidad y el placer experimentado a partir del cine en el espacio escolar cuando relata las conversaciones que suelen emerger con los estudiantes durante el tiempo de la clase: sobre la creación de suspenso en el cine a partir de los recursos narrativos 
que utiliza Quentin Tarantino en la secuencia inicial de Bastardos sin gloria (2009), al tener presente la explicación que al respecto da Alfred Hitchcock a François Truffaut; acerca de los dilemas éticos de la representación cinematográfica, a partir de las decisiones de Steven Spielberg en La lista de Schindler (1993). El siguiente testimonio agrega algunos elementos en este mismo sentido:

- El otro día hablábamos de eso: sobre la relación de la ética y la estética, y discutíamos. Algunos de los chicos habían visto Irreversible (2002), y yo les planteaba —cuando vi Irreversible, la escena de la violación me pareció tan fuerte que me pareció innecesaria-, que a mí estéticamente me había parecido que estaba muy lograda, pero que éticamente no me gustaba. Bueno, se generó una discusión en torno a eso. Los chicos habían visto Trainspotting (1996) también y plantearon algunas concepciones de metáforas que utiliza Danny Boyle, porque habían estado viendo Quién quiere ser millonario (2008), y la escena del final les hacía mucho ruido, todo lo que le pasa al pibe y terminan bailando. Bueno, les digo: "Fíjense cómo, con qué recurso, lo está usando a eso. Lo está planteando desde una perspectiva, como un recurso irónico, qué es lo que busca mostrar con esto" [...] Se dan esas discusiones.

Así, tal como sucede en el caso de Ramiro, estos intercambios constituyen rutinas también en las clases de Ignacio. Suelen emerger espontáneamente, a partir de sus propios intereses o de interrogantes que formulan los estudiantes. Asimismo, acostumbran a darse de manera imprevista, independientemente de la visualización —en el marco de la materia - de las películas referidas en los diálogos. Al respecto, Ignacio aclara que los estudiantes "las han visto por su cuenta", y agrega:

- Algunos después me las pidieron, después de que hablamos.

Esto da pie a la reflexión sobre la transmisión del cine y la cinefilia a partir de las prácticas de habla.

\section{Transmitir el discurso del cine -y las prácticas cinéfilas-en el aula}

"No abiertamente", afirma Ramiro respecto de si enseña a mirar cine cuando incorpora una película en sus clases. Luego de hacer una pausa reflexiva, continúa:

- Por ahí me desboco y pongo una pausa y digo: “¿Ven esto?”. Por ejemplo, estuve viendo Pequeño buda (1993) en un módulo de religión que yo les doy. Y, por ejemplo, hice hincapié en una escena de esas megaproducciones de antes con cien extras, que hay una escena que esta la madre de Siddharta agonizando, muriéndose, y tiene un séquito como de cien mujeres, y hace un paneo la cámara y les digo: “Miren eso! ¡Estas escenas ya no se ven más ahora!”. Pero esporádico esto, cuando no me contengo.

La premisa de transmitir el discurso del cine en tanto acto constituyente de la práctica cinéfila puede ser entendida en el marco de la misma teoría en que fue formulada, como la de transmitir el discurso de la cinefilia. Aun cuando en apariencia resulta tautológico quizá finalmente todo proceso de transmisión requiera de una repetición innecesaria de lo idéntico-, ese primer discurso del cine es el de las películas, pero también - ya que no puede ser de otra manera- el de las formas como las películas son miradas, conversadas y transmitidas. Dicho de otro modo: la única herramienta con la que cuentan los cinéfilos para transmitir el discurso del cine es su propia cinefilia que, a través de sus prácticas, termina configurando también ese discurso. Esta paradoja halla su resolución en la realización 
consecutiva de cada una de las propias prácticas cinéfilas: mirar, hablar y transmitir, para luego poder volver a mirar, hablar y transmitir. Sin embargo, la segunda vez, las prácticas son desplegadas junto a otros. No es por otro motivo que los Cahiers constituían clanes y los movie fans todavía construyen comunidades: para compartir con otros sus rituales y aficiones - mirar, hablar, transmitir colectivamente-. Aun cuando es imposible de comprobar, no es difícil especular sobre la improbable existencia de un solo cinéfilo entre los incontables anónimos que experimente placer a partir de una película sin compartirlo luego con otro $-\mathrm{y}$ no solo porque este enunciado contradice la construcción teórica que constituye su propia condición de existencia-. Si acaso pudo ser pensada como religión, es porque la cinefilia es, ante todo, un vínculo: con el cine, con los otros, con uno mismo. Dicho de otro modo, respectivamente: transmitir, hablar, mirar.

Si todo esto es cierto, pensar la transmisión del cine y las prácticas cinéfilas en la escuela requiere necesariamente seguir revisando lo anteriormente analizado: las prácticas cinéfilas de los docentes como espectadores y las prácticas pedagógicas de los cinéfilos como docentes; sus modos de mirar en la sala de cine y dar a mirar en el aula; sus modos de hablar de la calidad de las películas y de compartir con los estudiantes el placer que les producen; y, así, también sus modos de transmitir.

Resta todavía considerar un aspecto significativo de la cinefilia, omitido en la anterior elucubración: la cuestión de la pasión por el cine, si acaso fuera algo distinto del placer experimentado al mirar una película del modo que a uno más le guste y al compartir, por los medios que prefiera y con quien más desee, ese placer. En cualquier caso, el ejercicio del diccionario ofrece una rápida escapatoria. Entre otras acepciones, pasión refiere a una "perturbación o afecto desordenado del ánimo", a cierta "inclinación o preferencia muy viva" y al "apetito de algo o afición vehemente a ello" (Real Academia Española, s. f.). Sin embargo, estas imprecisiones no dejan entrever la pasión cinéfila con la claridad de la fugaz confesión de Ramiro: "cuando no me contengo".

\section{(In)certidumbres sobre un encuentro con el cine dentro de la escuela}

La transmisión del discurso del cine dentro de la escuela puede ser entendida también en los términos que propone Bergala (2007): "la cuestión del arte en la escuela es la del encuentro con la alteridad" (p. 33). Piensa en la posibilidad de que una transmisión de ese modo tenga lugar en el espacio, ajustarse al tiempo y desplegarse más allá de las rígidas normas y las formas cristalizadas del trabajo escolar tradicional.

El arte, por definición, siembra desconcierto en la institución [...] [Es] un germen de anarquía, escándalo y desorden [...] [Y, de esta manera,] cualquier forma de encerramiento en la lógica disciplinar reduce el alcance simbólico del arte y su potencia de revelación, en el sentido fotográfico del término. (p. 33)

La intención de producir un encuentro con el cine en ese sentido de cierta manera puede advertirse en algunas de las prácticas reseñadas de Ignacio y de Ramiro. En sus testimonios, por sobre la potencia reveladora del arte, destaca más "el papel no desdeñable" de la escuela, entendida como "el único lugar donde este encuentro con el arte puede producirse" para la mayoría de los jóvenes, expuestos cotidianamente a las "mercancías culturales de rápido consumo, rápida caducidad y socialmente obligatorias" (Bergala, 2007, p. 36). 
Sin embargo, pese a la realización de estas actividades que giran en torno a las prácticas de transmitir un cierto repertorio cinematográfico, los docentes entrevistados no son ingenuos respecto de que un encuentro planteado en estos términos puede o no suceder. En efecto, el tratado de Bergala (2007) contempla que:

Se puede obligar a aprender, pero no se puede obligar a sentirse conmovido. Todos sabemos que los libros, las películas, los pasajes musicales que han sido importantes en nuestra vida, los hemos descubierto individualmente, en la intimidad, en el interior de uno mismo, incluso cuando aparentemente ese encuentro ha tenido lugar en una situación de grupo o de transmisión instituida [...] Este encuentro tiene más que ver con una iniciación que con el aprendizaje, y la escuela nunca podrá programarlo ni garantizarlo. Como todo encuentro verdadero, también no puede producirse nunca en su potencia de revelación y de conmoción personales. (p. 63)

De esta manera, más allá de las prácticas analizadas respecto de los actos de mirar, mostrar, hablar y transmitir el discurso cinéfilo sobre el cine en la escuela, no es evidente que un encuentro que genere desconcierto, escándalo y revelación ocurra en el contexto de la incorporación de películas que realizan estos docentes. Sin embargo, también es cierto que ninguno de ellos plantea exactamente así el horizonte de sus prácticas.

Finalmente, teniendo esto en cuenta y sin forzar la teoría ni las prácticas, es posible advertir algunos rasgos de esta hipótesis del cine - acaso con la fugacidad y opacidad que un encuentro con semejante características permite-, por ejemplo, cuando, sin que medien otros objetivos, el cine es incorporado como fin en sí mismo, sin más: "No sé, se me ocurrió pasarlo", cuenta Ignacio, a propósito de aquella vez que compartió con los estudiantes la película de cortometraje Lamb (2002):

- Viste que a veces te sobran 5 minutos [de clase] y decís: "Paso 5 minutos de algo".

Resume la historia narrada en el cortometraje como la relación de un padre y un hijo que:

- Están muertos de hambre, comen un potaje asqueroso que ni el perro come, y tiene un cordero. El chico es ciego. Y va mostrando cómo lleva el cordero siguiendo una soga. Es sumamente impactante. $Y$ en un momento al padre se le ocurre sacrificar al cordero. Comen. Casi no tiene diálogo. Y el chico toma la soga para ir a acariciar su cordero, y es el perro disfrazado con la piel del cordero. Es una cosa bastante perversa.

En tanto pasador o mediador en el sentido que propone Bergala (2007), Ignacio repite que decidió proyectarlo:

- Para que lo vean, nada más: "Miren esto; si quieren verlo, véanlo; si no quieren, no lo vean".

$\mathrm{Y}$, junto con esto, las conclusiones que comparte sobre esta experiencia permiten pensar un encuentro con el cine en términos de Bergala (2007), más allá de los rumbos que luego haya tomado la actividad. Cuenta Ignacio:

- Terminó generando toda una discusión; pero de la nada, sin que lo pretendiera. [...] Había chicas que eran vegetarianas y salió toda una cuestión en torno a la discusión de la carne. [...] [También sobre] lo perversa que era la relación del padre: si debía priorizar al hijo, el sentido ético, si tenía que llenarle la panza. [Siempre surgen discusiones] mientras se plantee 
la cuestión con respeto hacia sus compañeros, o sea, que le den el espacio a hablar y a discutir [...] Hay que dejarlas fluir.

En seguida, el relato de la experiencia conduce a Ignacio a constatar la emergencia de emociones por parte de los estudiantes en estas clases. En este sentido, con la premeditación que caracteriza su testimonio, afirma:

- Me parece que [la ficción cinematográfica] aporta la cuestión de la emotividad [...] Hay una cuestión desde lo emotivo que el documental no logra. Más allá de la cuestión del impacto, que es un proceso de identificación de los espectadores con los personajes, uno se identifica con cierta cuestión de los personajes, construye ciertos mundos, proyecta ciertos mundos también, ciertos deseos, sobre el personaje en cuestión [...] No sé si me interesa que pase, [pero] sé que ocurre. Y por ahí es interesante. Sobre todo, en la edad de los chicos, hay identidades bastante complejas o poco definidas o todavía por definirse. Me parece interesante cómo toman posiciones y a veces después cómo cambian posiciones en función de otras lecturas que hacen del material.

Por supuesto, como no puede ser de otra manera en coherencia con sus objetivos pedagógicos, Ignacio cuenta que trata de "convertir ese proceso emotivo en un proceso racional". Propone a los estudiantes:

- No nos quedemos con la cuestión que nos quedó, que nos generó emoción, por la emoción misma, sino ver qué puede haber de fondo, qué hay racionalmente en la construcción de esa emoción.

Sin embargo, aun cuando esta operación propiamente escolar pretende ceñir la afectación producida por el cine, "quizá algo ya haya quedado", porque, tal como sostiene Bergala (2007):

En el momento del encuentro, uno se contenta con recoger el enigma con asombro y acusar su golpe, su poder de conmoción. El tiempo de la elucidación vendrá después y podrá durar veinte años, treinta, o toda una vida. La película trabaja en sordina, su onda de expansión se extiende lentamente. (p. 63)

Esto es algo que parecen tener claro Ignacio y Ramiro como cinéfilos y docentes, y por eso acaso no les preocupa. Dice Ramiro:

- Yo les abro ese juego [...] después algunos lo toman, otros ni pelota, otros ni se enteran [...] [pero] algunos se enganchan. Ven una peli.

En el mismo sentido, Ignacio afirma que "muchos de los chicos se enganchan" y aclara:

- No son todos, obviamente, algunos están viendo el techo [...] No es algo que pueda controlar, ni que me interese controlar tampoco: hay cosas que a uno definitivamente no le interesan y que forzarlas no tiene ningún sentido.

Quizás, al dar cuenta de esa imprecisa e imprevisible transmisión que refiere Bergala (2007), Ignacio concluye:

- Pero los que se enganchan, generalmente después te empiezan a pedir películas. 


\section{Referencias}

Abramowski, A. (2015). La escuela y su hacer con las imágenes. Educación, Cine y Fotografía [Clase no publicada]. FLACSO/Argentina.

Arfuch, L. (1995). La entrevista, una invención dialógica. Paidós.

Benasayag, A. (2012). El cine de ficción en la escuela argentina. Revisión histórica, hipótesis de trabajo y nuevas interrogantes. Revue Ensemble, 8(4), 1-13.

Benasayag, A. (2017). La hipótesis de la cinefilia docente. El cine de ficción en la escuela media argentina. Revista Digital do Laboratório de Artes Visuais, 10(2), 56-78. https:// doi.org/10.5902/1983734827504.

Benasayag, A. (2020). Discusiones en torno a la relación entre cine y escuela. De omisiones, reduccionismos y posibilidades en la experiencia argentina ante el itinerario del sistema educativo francés. Saberes y Prácticas, 5(2). http://revistas.uncu.edu.ar/ojs/index.php/ saberesypracticas/article/view/4007.

Bergala, A. (2007). La hipótesis del cine. Laertes.

Baecque de, A. \& Frémaux, T. (1995). La cinéphilie ou l'invention d'une culture. Vingtième Siècle. Revue d'histoire, 46, 133-142. https://doi.org/10.2307/3771553.

Dussel, I. (2014). Usos del cine en la escuela: una experiencia atravesada por la visualidad. Estudos da Língua(gem), 12(1), 77-100. https://doi.org/10.22481/el.v12i1.1241.

Dussel, I., Ferrante, P., González, D., Benasayag, A., Montero, J., Laguzzi, G., Piracón, J., \& Zampieri, D. (2011). Escuelas, jóvenes y saberes [Informe de investigación no publicado]. FLACSO/Argentina.

Jenkins, H. (2009). Fans, blogueros y videojuegos. La cultura de la colaboración. Paidós.

Jullier, L., \& Leveratto, J. (2012). Cinéfilos y cinefilias. La marca.

Paladino, D. (2006). Qué hacemos con el cine en el aula. En I. Dussel, \& D. Gutiérrez (Eds.), Educar la mirada: políticas y pedagogías de la imagen (pp. 135-144). Manantial.

Real Academia Española. (s. f.). Pasión. En Diccionario de la lengua española. Recuperado el 20 de octubre de 2020, de https://dle.rae.es/pasión.

Robnik, D. (2005). Mass Memories of Movies. En M. de Valck, \& M. Hagener, (Eds.) Cinephilia. Movies, love and memory (pp. 55-64). Amsterdam University Press. https:// doi.org/10.25969/mediarep/3685.

Serra, M. (2011). Cine, escuela y discurso pedagógico. Teseo.

Staiger, J. (2005). Media reception studies. New York University Press.

Valck de, M., \& Hagener, M. (Eds.). (2005). Cinephilia. Movies, love and memory. Amsterdam University Press. https://doi.org/10.25969/mediarep/3685. 